\title{
Perbandingan Metode Analytical Hierarchy Process (AHP) dan Himpunan Keanggotaan Fuzzy pada Penilaian Kinerja Dosen
}

\author{
Noni Namida Oliviani*, Haris Rafi**, Mochammad Febri Hariyadi***, Nova El Maidah**** \\ Program Studi Teknologi Informasi, Universitas Jember \\ "noninamida.nn@gmail.com, ${ }^{* *}$ harisrafi820@gmail.com, ${ }^{* * *}$ febrihariyadi@gmail.com, \\ ****nova.pssi@unej.ac.id
}

\begin{abstract}
Utilization of artificial intelligence has been imposed into many things, one of them on the assessment of lecturer's performance, one of them on the lecturer's performance assessment. Artificial intelligence can help and facilitate a person to solve a particular problem. In general, the purpose of lecturer performance assessment is to determine the best lecturer's order through predetermined criteria. Decision Making Method (AHP) and Function Membership Fuzzy is a method often used to determine lecturer performance assessment. There is a method that is a form of calculation whose output is the value of several lecturers who entered the assessment list. The purpose of the comparison is to know which artificial intelligence method is best applied to the lecturer's performance assessment. The method used to test the artificial intelligence applied to the lecturer's performance assessment is to use a comparison scenario. Based on the analysis that has been done, the result that artificial intelligence using AHP method and Membership Sets Fuzzy have balanced result. Based on the document can be concluded that in this study AHP method is a superior method in terms of accuracy, while the Fuzzy method is superior in terms of effectiveness.
\end{abstract}

Keyword: Lecturer Performance, Artificial intelligence, Analytical Hierarchy Process, Function Membership Fuzzy

\section{Introduction}

Perkembangan teknologi saat ini sangat pesat, sehingga dapat dimanfaatkan untuk membantu pekerjaan manusia. Salah satunya yaitu melakukan penilaian terhadap kinerja dosen. Aktivitas untuk melakukan penilaian kinerja dosen sangat diperlukan di setiap perguruan tinggi. Karena setiap perguruan tinggi pasti memiliki tujuan untuk menciptakan lulusan-lulusan yang berkualitas. Oleh karena itu, sangat dibutuhkan dosen-dosen yang berkompeten dalam pengajaran.

Metode AHP merupakan suatu metode untuk membuat urutan alternatif keputusan dan pemilihan alternatif terbaik pada saat pengambilan keputusan dengan beberapa tujuan atau kriteria untuk mengambil keputusan tertentu. Dengan metode AHP penilaian kinerja dosen dapat terpenuhi dengan beberapa kriteria didalamnya. Selain metode AHP, penilaian kinerja dosen juga bisa didapatkan dengan menggunakan fungsi keanggotaan himpunan Fuzzy. Himpunan keanggotaan Fuzzy merupakan yang digunakan untuk mengatasi hal yang tidak pasti pada masalah-masalah yang mempunyai banyak jawaban. Penalaran Logika Fuzzy menyediakan cara untuk memahami sistem dengan cara menilai input dan output informasi yang samarsamar.

Penelitian [1], digunakan metode AHP dalam proses penilaian kinerja dosen. Metode ini digunakan untuk menentukan urutan dosen terbaik, melalui 4 kriteria yaitu kehadiran dosen, pengumpulan nilai, keterlambatan masuk, dan keluar proses belajar mengajar. Penelitian yang serupa [2] digunakan metode Fuzzy Sugeno dalam proses menentukan penilaian kinerja dosen. Metode ini di gunakan untuk mencari nilai dosen yang paling optimal dengan membandingakan hasil penalaran fuzzy pada prediksi nilai dosen terbaik dengan membandingkannya dengan nilai dosen yang sesungguhnya. Penelitian serupa [3] menggunakan metode AHP dalam proses menentukan penilaian kinerja karyawan. Metode ini digunakan untuk menentukan layak tidaknya karyawan untuk dipromosikan ke jabatan yang lebih tinggi dengan mempertimbangkan 8 hal. Penelitian [4] memnggunakan metode Fuzzy Sugeno dalam proses evaluasi kinerja karyawan yang mempermudah menejerial.

Kedua cara ini sangat membantu dalam melakukan penilaian terhadap kinerja dosen pada setiap perguruan tinggi. Pada prinsipnya penilaian kinerja merupakan cara pengukuran kontribusi dari individu dalam instansi yang dilakukan terhadap organisasi. Nilai penting dari penilaian kinerja adalah menyangkut penentuan tingkat kontribusi individu atau kinerja yang diekspresikan dalam menyelesaikan tugas - tugas yang menjadi tanggung jawabnya. Tetapi, berbeda metode tentu berbeda pula cara menentukan penilaiannya. Oleh karena itu, penelitian ini dilakukan untuk membandingkan metode AHP dengan himpuanan keanggotaan Fuzzy dalam keakuratan menentukan penilaian terhadap kinerja dosen. 


\section{Research Method}

A. Metode Analytical Hierarchy Process (AHP)

Analytical Hierarchy Process (AHP) dikembangkan oleh Thomas L. Saaty pada tahun 1970-an. Metode ini merupakan salah satu model pengambilan keputusan multikriteria yang dapat membantu kerangka berpikir manusia dimana faktor logika, pengalaman pengetahuan, emosi dan rasa dioptimasikan ke dalam suatu proses sistematis. Pada dasarnya, AHP merupakan metode yang digunakan untuk memecahkan masalah yang kompleks dan tidak terstruktur ke dalam kelompok-kelompoknya, dengan mengatur kelompok tersebut ke dalam suatu hierarki, kemudian memasukkan nilai numerik sebagai pengganti persepsi manusia dalam melakukan perbandingan relatif. Dengan suatu hipotesa maka akan dapat ditentukan elemen mana yang mempunyai prioritas tertinggi [5].

Secara umum, tahapan-tahapan proses yang harus dilakukan dalam menggunakan AHP untuk memecahkan suatu masalah adalah sebagai berikut :

1. Mendefenisikan permasalahan dan menentukan tujuan. Bila AHP digunakan untuk memilih alternatif atau menyusun prioritas alternatif, maka tahap ini dilakukan pengembangan alternatif.

2. Menyusun masalah ke dalam suatu struktur hierarki sehingga permasalahan yang kompleks dapat ditinjau dari sisi yang detail dan terukur.

3. Menyusun prioritas untuk tiap elemen masalah pada setiap hierarki. Prioritas ini dihasilkan dari suatu matriks perbandingan berpasangan antara seluruh elemen pada tingkat hierarki yang sama.

Melakukan pengujian konsistensi terhadap perbandingan antar elemen yang didapatkan pada tiap tingkat hierarki. Thomas L. Saaty membuktikan bahwa Indeks Konsistensi dari matriks berordo -n )[6].

Ada beberapa dosen yang masuk dalam kriteria penilaian, yaitu :

1. Dosen 1

2. Dosen 2 ini.

Dari informasi diatas kemudian disusun hirarki antara kriteria dan alternative, seperti gambar 1 berikut

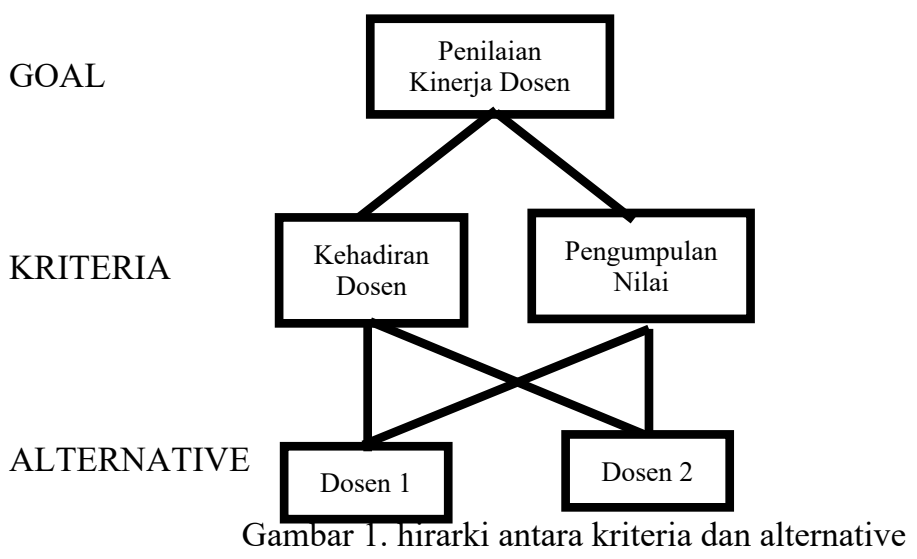

Informasi yang ada kemudian di-sintesis untuk menentukan peringkat relative dari alternative pilihan yang ada. Kriteria dari jenis qualitative dan quantitative dapat diperbandingkan menggunakan informed judgement untuk menghitung bobot dan prioritas. Hal ini dapat dilakukan dengan judgement untuk menentukan peringkat dari kriteria.

1. Membuat Matriks Perbandingan Kriteria

Tahapan ini pemberian bobot masing-masing kriteria menggunakan model AHP (Analytical Hieracrchy Process). Data kriteria didapatkan dari pihak sumber yang langsung membandingkan kriteria dan kriteria sesuai dengan tabel kepentingan dan sampel hasil matriks perbandingan berpasangan terlebih dahulu. TABEL 1 menunjukan matriks perbandingan berpasangan kriteria. TABEL 2 dan 3 merupakan tabel matrik perbandingan pasangan alternatif masing-masing kriteria Kehadiran Dosen dan Pengumpulan Nilai.

Tabel 1 Matriks Perbandingan Berpasangan Kriteria

\begin{tabular}{|l|l|l|}
\hline Kriteria & KD & PN \\
\hline KD & $1 / 1$ & $3 / 1$ \\
\hline $\mathrm{PN}$ & $1 / 3$ & $1 / 1$ \\
\hline
\end{tabular}


Tabel 2 Matriks Perbandingan Berpasangan Alternative Berdasarkan Kriteria Kehadiran Dosen

\begin{tabular}{|l|l|l|}
\hline KD & DS & DD \\
\hline DS & $1 / 1$ & $2 / 1$ \\
\hline $\mathrm{DD}$ & $1 / 2$ & $1 / 1$ \\
\hline
\end{tabular}

Tabel 3 Matriks Perbandingan Berpasangan Alternative Berdasarkan Kriteria Pengumpulan Nilai

\begin{tabular}{|l|l|l|}
\hline PN & DS & DD \\
\hline DS & $1 / 1$ & $4 / 1$ \\
\hline DD & $1 / 4$ & $1 / 1$ \\
\hline
\end{tabular}

B. Himpunan Keanggotaan Fuzzy

Himpunan keanggotaan [7] dari suatu himpunan fuzzy dinyatakan dengan derajat keanggotaan suatu nilai terhadap nilai tegasnya yang berkisar antara 0.0 sampai dengan 1.0. Fungsi keanggotaan adalah sebuah kurva yang menunjukkan titik input kedalam nilai keanggotaanya. Untuk mendapatkan nilai keanggotaan dapat menggunakan pendekatan fungsi sebagai berikut :

1. Representasi Linier

Pada representase linier, pemetaan input ke derajat keanggotaannya digambarkan sebagai garis lurus. Bentuk ini adalah menjadi paling sederhana dan menjadi pilihan yang baik untuk mendekati suatu konsep yang kurang jelas.

2. Representase Kurva Segitiga

Kurva segitiga pada dasarnya merupakan gabungan dari 2 garis linier.

3. Representasi Kurva Trapesium

Kurva travesium pada dasarnya sama dengan kurva segitiga, namun ada beberapa titik yang memiliki nilai keanggotaan 1

4. Representasi Kurva- S

Kurva pertumbuhan dan penyusutan merupakan kurva-S (sigmoid) yang berhubungan dengan kenaikan dan penurunan permukaan secara tak linier. Kurva S untuk pertumbuhan akan bergerak dari sisi paling kiri untuk nilai keanggotaan 0 ke sisi paling kanan yang nilai keanggotaan 1. Pada kurva ini bahwa nilai keanggotaannya akan bertumpu pada 50\% nilai keanggotaannya atau yang sering disebut dengan titik infeksi [8].

5. Representase Kurva Bahu

Daerah yang terletak ditengahtengah suatu variabel yang direpresentasikan dengan segitiga, dan pada sisi kanan dan kirinya akan naik dan turun, dan pada nilai tertentu tidak mengalami perubahan. Himpunan fuzzy bahu yang bukan segitiga digunakan untuk mengakhiri variabel suatu daerah fuzzy dimana bahu kiri akan bergerak dari nilai keanggotaan 1 kenilai keanggotaan 0 , sedangkan bahu kanan akan bergerak dari nilai keanggotaan 0 kenilai keanggotaan 1.

6. Representase Kurva Bell

Bentuk lain dari kurva fuzzy adalah kurva bell, dimana nilai keanggotaan dipengaruhi oleh nilai tengah dari domain.

Himpuan keanggotaan Fuzzy yang digunakan dalam pengukuran kinerja dosen adalah kurva trapesium dan kurva bahu (kiri dan kanan).

Himpunan keanggotaan Fuzzy digunakan untuk merepresentasikan kriteria Kehadiran Dosen dan Pengumpulan Nilai.

1. Fungsi Keanggotaan Fuzzy berdasarkan Kriteria Kehadiran Dosen
Buruk $=\{0-70\}$
Cukup $=\{65-80\}$
Baik $=\{73-100\}$

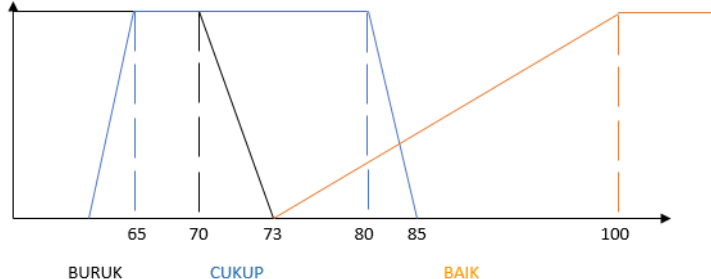

Gambar 2. Fungsi Keanggotaan Kriteria Kehadiran Dosen

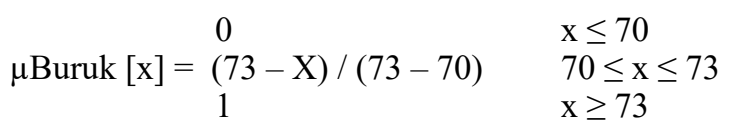




$$
\begin{array}{rlr}
\mu \text { Cukup }[\mathrm{x}]= & (\mathrm{x}-60) /(65-60) & \mathrm{x} \leq 60 / \mathrm{x} \geq 85 \\
1 & 60 \leq \mathrm{x} \leq 65 \\
& 65 \leq \mathrm{x} \leq 80 \\
& (85-\mathrm{x}) /(85-80) & 80 \leq \mathrm{x} \leq 85 \\
& 0 & \\
\mu \text { Baik }[\mathrm{x}]= & (\mathrm{x}-73) /(100-73) & 73 \leq \mathrm{x} \leq 100 \\
1 & \mathrm{x} \geq 100
\end{array}
$$

2. Fungsi Keanggotaan Fuzzy berdasarkan Kriteria Pengumpulan Nilai

$$
\begin{array}{ll}
\text { Terlambat } & =\{0-75\} \\
\text { Tepat } & =\{70-100\}
\end{array}
$$

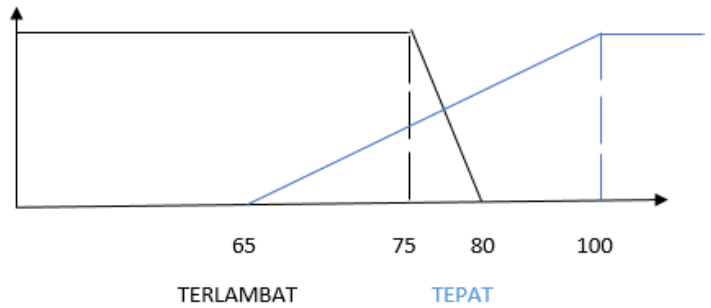

Gambar 3 Fungsi Keanggotaan Kriteria Pengumpulan Nilai

$$
\begin{aligned}
& \mu \text { Terlambat }[\mathrm{x}]=\begin{array}{cl}
0 & \mathrm{x} \leq 75 \\
(80-\mathrm{X}) /(80-75) & 75 \leq \mathrm{x} \leq 80 \\
1 & \mathrm{x} \geq 80
\end{array} \\
& \mu \text { Tepat }[\mathrm{x}]=\begin{array}{ll}
0 & \mathrm{x} \leq 65 \\
(\mathrm{x}-65) /(100-65) & 65 \leq \mathrm{x} \leq 100
\end{array} \\
& 1 \geq 100
\end{aligned}
$$

\section{Result and Analysis}

A. Penilaian Menggunakan Metode AHP

1. Hasil Analisa Metode AHP

Hasil Analisa bobot dari kriteria seperti ditunjukan pada TABEL 4 yang merupakan tabel perbandingan berpasangan kriteria Kehadiran Dosen dan Pengumpulan Nilai antara Dosen 1 dan Dosen 2. Matriks perbandingan alternatif masing-masing kriteria Kehadiran Dosen dan Pengumpulan Nilai ditunjukkan pada TABEL 5 dan 6 .

Tabel 4 Hasil Analisa Kriteria

\begin{tabular}{|c|c|c|c|}
\hline Kriteria & KD & PN & Eigen \\
\hline KD & 1.0 & 3.0 & 0.75 \\
\hline PN & 0.33 & 1.0 & 0.24 \\
\hline
\end{tabular}

Tabel 5 Hasil Analisa Alternative Berdasarkan Kriteria Kehadiran Dosen

\begin{tabular}{|c|c|c|c|}
\hline KD & DS & DD & Eigen \\
\hline DS & 1.0 & 2.0 & 0.5 \\
\hline DD & 0.5 & 1.0 & 0.5 \\
\hline
\end{tabular}

Tabel 6 Hasil Analisa Alternative Berdasarkan Kriteria Pengumpulan Nilai

\begin{tabular}{|c|c|c|c|}
\hline PN & DS & DD & Eigen \\
\hline DS & 1.0 & 4.0 & 0.95 \\
\hline DD & 0.25 & 1.0 & 5.25 \\
\hline
\end{tabular}

Tabel 7 Hasil Analisa Perhitungan Ranking

\begin{tabular}{|c|c|c|c|c|}
\hline \multirow{2}{*}{ Bobot } & KD & PN & Bobot & Rank \\
\cline { 2 - 3 } & 0.75 & 0.24 & Final & \\
\hline DS & 0.5 & 0.95 & 0.60 & 2 \\
\hline DD & 0.5 & 5.25 & 1.63 & 1 \\
\hline
\end{tabular}


Didapatkan kesimpulan bahwa Dosen 2 mendapat peringkat pertama sebagai dosen dengan penilaian kinerjanya paling baik. Dosen 1 peringkat kedua.

1. Dosen 2 (Peringkat Pertama)

2. Dosen 1 (Peringkat Kedua)

B. Penilaian Menggunakan Metode Fungsi Keanggotaan Fuzzy

Dari Gambar.4, dapat dicari fungsi keanggotaanya yaitu seperti sebagai berikut :

$$
\begin{aligned}
\text { Dosen } 1[\mathrm{x}] & =88 \\
\mu \text { Dosen } 1[88] & =(\mathrm{x}-\mathrm{A}) /(\mathrm{B}-\mathrm{A}) \\
& =(88-73) /(100-73) \\
& =15 / 27 \\
& =0,5 \\
\operatorname{Dosen} 2[\mathrm{x}] & =85 \\
\mu \operatorname{Dosen} 2[85] & =(\mathrm{x}-\mathrm{A}) /(\mathrm{B}-\mathrm{A}) \\
& =12 / 27 \\
& =0,4
\end{aligned}
$$

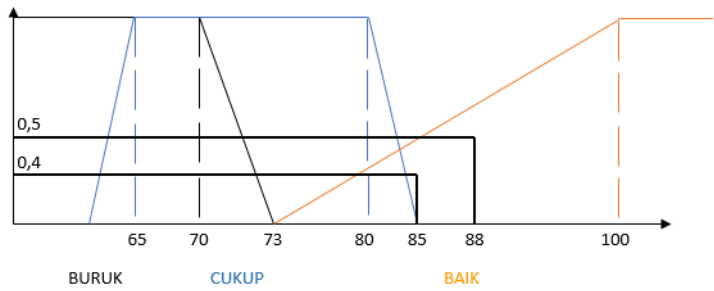

Gambar. 4 Derajat Keanggotaan Kriteria Kehadiran Dosen

Dari gambar 5, dapat dicari fungsi keanggotaanya yaitu seperti sebagai berikut.

$$
\begin{aligned}
\text { Dosen } 1[\mathrm{x}] & =77 \\
\mu \operatorname{Dosen} 1[77] & =(\mathrm{B}-\mathrm{x}) /(\mathrm{B}-\mathrm{A}) \\
& =(80-77) /(80-75) \\
& =0,6 \\
\operatorname{Dosen} 2[\mathrm{x}] & =85 \\
\mu \operatorname{Dosen} 1[85] & =(\mathrm{x}-\mathrm{A}) /(\mathrm{B}-\mathrm{A}) \\
& =(85-65) /(100-65) \\
& =0,5
\end{aligned}
$$

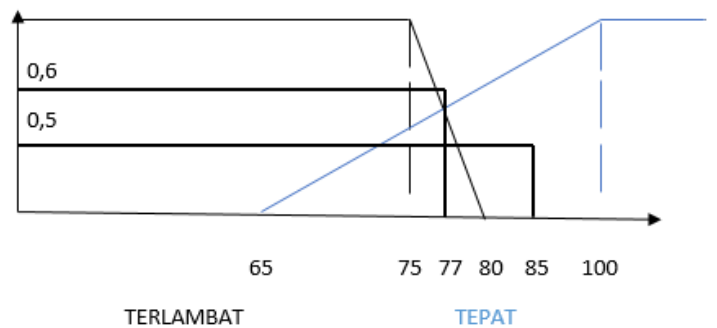

Gambar. 5 Derajat Keanggotaan Kriteria Pengumpulan Nilai

\section{Conclusion}

1. Metode Analythical Hierarchy Process (AHP) dan Fungsi Keanggotaan Fuzzy dapat digunakan untuk penilaian kinerja dosen.

2. Dari hasil pengujian, tingkat keefektifan dalam melakukan penilaian kinerja dosen ini terdapat pada metode Fuzzy tetapi dari segi keakuratan dalam melakukan penilaian kinerja dosen ini terdapat pada metode AHP.

3. Salah satu perbedaan metode ini juga terdapat pada hasil akhir. Metode AHP mengeluarkan hasil akhir berupa peringkat, sedangkan fungsi keanggotaan Fuzzy hasil akhir berupa nilai. 
4. Kekurangan dari kedua metode ini yaitu proses yang cukup kompleks. Sehingga tanpa ketelitian dan kecermatan dalam melakukan proses pencarian, bisa memberikan hasil yang tidak tepat.

\section{Acknowledgements (10 PT)}

Penelitian ini merupakan keluaran dari tugas besar mata kuliah SPPK yang dibimbing oleh ibu Nova Al Maidah.

\section{References}

[1] Ria Eka Sari dan Alfa Saleh., 2014. Penilaian Kinerja Dosen Dengan Menggunakan Metode AHP (Studi Kasus: Di Stmik Potensi Utama Medan), Seminar Nasional Informatika 2014.

[2] Magdalena Simanjuntak., 2017. Penilaian Kinerja Dosen Dengan Menggunakan Metode Sugeno, Jurnal ISD Vol.2 No.1 Januari - Juni 2017 pISSN : 2477-863X eISSN : 2528-5114.

[3] Rizka Shoumil Ilhami dan Dino Rimantho., 2017. Penilaian Kinerja Karyawan dengan Metode AHP dan Rating Scale, JURNAL OPTIMASI SISTEM INDUSTRI - VOL. 16 NO. 2 (2017) 150-157

[4] Fanisya Alva Mustika dan Sutrisno., 2016. Model Evaluasi Kinerja Karyawan Dengan Metode Fuzzy Sugeno Pada Resto Abtl, Jurnal String Vol. 1 No. 1 Tahun 2016 ISSN: 2527 - 9661

[5] Hilyah Magdalena., 2012. Sistem Pendukung Keputusan Untuk Menentukan Mahasiswa Lulusan Terbaik di Perguruan Tinggi, Jurnal Teknologi Informasi dan Komunikasi ISSN:2089-9815. Hal.50 sd 51.

[6] Yusuf Anshori., 2012. Pendekatan Triangular Fuzzy Number Dalam Metode Analytical Hierarchy Process, Jurnal Ilmiah Foristek Vol.2 No.1. Hal.127.

[7] Pirmando Gultom, S.Kom,. M.Kom., 2015. Model Fungsi Keanggotaan Fuzzy Multi Criteria Decision Making Pada Program Sertifikasi Guru, Jurnal Ilmiah Research Sains Vol.1 No.3.

[8] Earl Cox, 1994, "Compiling and Using the C++ Fuzzy Modelling Code in The Fuzzy Systems Handbook",Academik Press Limited 